Article

\title{
Environmental Inequality in China: A "Pyramid Model" and Nationwide Pilot Analysis of Prefectures with Sources of Industrial Pollution
}

\author{
Qi He ${ }^{1,2,3} \mathbb{B}$, Hong Fang ${ }^{1, *}$, Han Ji ${ }^{4, *}$ and Siran Fang ${ }^{5}$ \\ 1 School of Economics and Management, Beihang University, Beijing 100191, China; qqleslie-32@163.com \\ 2 Ministry of Education Key Laboratory for Earth System Modelling, Department of Earth System Science, \\ Tsinghua University, Beijing 100084, China \\ 3 ESRC Centre for Climate Change Economics and Policy (CCCEP), School of Earth and Environment, \\ University of Leeds, Leeds LS2 9JT, UK \\ 4 Agricultural Information Institute, Chinese Academy of Agricultural Sciences, Beijing 100081, China \\ 5 College of Engineering, Nanjing Agricultural University, Nanjing 210031, China; siranfang@163.com \\ * Correspondence: fanghong@buaa.edu.cn (H.F.); jihan@caas.cn (H.J.); \\ Tel.: +86-010-8233-9023 (H.F.); +86-010-8210-9917 (H.J.)
}

Received: 26 August 2017; Accepted: 16 October 2017; Published: 18 October 2017

\begin{abstract}
In China, environmental pollution generated via industrialization as well as profound changes in the social structure and the gradual maturation of the social hierarchy have jointly contributed to the Chinese people's increased environmental consciousness and appeals for environmental justice (EJ). Because of the absence of an EJ theory and a lack of empirical research focused on China, this paper proposes a "Pyramid Model" for EJ research in China that includes the following three factors: basic demographic and socioeconomic characteristics, U.S.-based EJ principles, and Chinese characteristics. A nationwide pilot analysis of environmental inequality at the prefecture level is conducted by empirically examining the association between the demographic variables and socioeconomic status with sources of industrial pollution in China. The prefecture-based results are shown to be robust, and they indicate that areas inhabited by ethnic minorities and western regions of China carry disproportionate environmental burdens. However, a different picture for migrants is presented, revealing that Chinese migrants are not currently exposed to greater levels of industrial pollution. Relevant interpretations of these findings are provided. The results also show that environmental inequality associated with income level, which is observed in the U.S., does not occur in China.
\end{abstract}

Keywords: environmental inequality; environmental justice; industrial pollution; prefectures; demographic and socioeconomic factors; China

\section{Introduction}

During the "12th Five-year Plan" (implemented from 2011 to 2015), with an annual economic growth of $7.8 \%$, China reduced its total emissions of major pollutants such as sulphur dioxide $\left(\mathrm{SO}_{2}\right)$, chemical oxygen demand (COD) and nitrogen oxide $\left(\mathrm{NO}_{\mathrm{x}}\right)$ by $18 \%, 12.9 \%$ and $18.6 \%$ (data drawn from State Council document No. 74 (2016) issued by the State Council of China; see details at http:/ / www.gov.cn/zhengce/content/2017-01/05/content_5156789.htm (in Chinese)), respectively, which exceeded the requirements of the state plan. However, reducing the tendency towards environmental deterioration in China is difficult. Since 1996, the occurrence of massive environmental incidents has maintained an average annual growth rate of $29 \%$, with a higher risk of emergent environmental events associated with heavy metals and hazardous chemicals. In addition, a $120 \%$ annual increase in significant environmental events was observed in 2011. ("Massive environmental 
incidents" refer to the events caused by spills and releases of pollutants that affect the demand for clean air, water, soil, etc. According to the classification standards for environmental incidents issued by the Ministry of Environmental Protection of China, environmental incidents can be categorized into four groups (mega, significant, major and general events) based on their severity (Ministry document No. 34 from 2015); see details at http://www.zhb.gov.cn/gkml/hbb/bl/201504/t20150429_299852.htm. "Emergent environmental events" refer to emergencies that cause the environment to be polluted or damaged due to accidents that endanger or threaten the lives, health and property of the public; see detailed information on environmental incidents at http://news.sohu.com/20121027/n355822896. shtml (in Chinese)) These data highlight the urgent need for environmental justice (EJ) in China, as the Chinese public is subject to enormous resource and environmental pressures.

Given the U.S. public's serious concerns regarding EJ issues and policymakers' struggles with environmental injustice, a considerable amount of scholarly research has been conducted to evaluate whether geographical units with higher proportions of minorities [1-3] and lower-income populations [4-6] are disproportionately subjected to environmental burdens. After decades of development, these race- and class-based empirical studies have primarily employed three types of methodologies: unit-based [7], distance-based [8-10] and exposure- or risk-based analyses [11-13].

In China, although environmental protection has gradually permeated the dominant ideology, the concepts of environmental equality and EJ are not as well understood, and this urgent topic has yet to be systematically explored. In addition to data limitations, the issue of environmental inequality in China has received comparatively insufficient attention in the academic and political domains, and studies on these related topics are surprisingly limited, despite the increasing calls for EJ from the public, non-governmental organizations (NGOs), environmental activists and even the media [14-16]. To date, despite the many excellent case studies performed on pollution and environmental disasters and numerous journalism reports on this subject, systematic and quantitative research on the groups most affected by pollution in China is relatively lacking, with limited exceptions, such as Quan (2001) [17], Ma (2010) [18] and Schoolman and Ma (2012) [19].

Quan (2001) [17] proposed a pioneering EJ research model that takes China's social and economic background into consideration. In examining the development, implementation and enforcement of environmental laws, regulations, and policies as well as the extent of meaningful involvement in the decision-making processes of the government and the distribution of environmental burdens and benefits, Quan interpreted EJ in China as consisting of fair treatment for people of all races, incomes and occupations regardless of gender, residence, educational level, age, political position or background. Due to the limited applicability of U.S. race- and income-based models for studies of EJ in China, Quan proposed models based on specific population groups that are suffering adverse environmental effects and, for the first time, highlighted "migrant workers" in research on EJ in China. Thereafter, Ma (2010) [18] and Schoolman and Ma (2012) [19] presented the most thorough systematic studies of environmental inequality in China. Empirically treating the township level as the spatial unit of analysis, both studies examined environmental inequality in China using a dataset of industrial pollution sources from the Environmental Protection Bureaus (EPBs) of Henan and Jiangsu provinces, and they found that migrants from the poor countryside are exposed to a disproportionate amount of pollution, even after controlling for other key factors.

Although the scholars mentioned above have attempted to break the stalemate in Chinese EJ research, additional work is required to enrich the current academic output and construct a theoretical framework of EJ research that takes China-specific characteristics into account. As EJ and environmental inequality are considered to be comparative concepts, we define EJ from a distributional perspective as follows: People of all different races, education levels, and other backgrounds must receive a fair share of environmental burdens and environmental benefits. Correspondingly, environmental inequality is defined as shouldering a disproportionate environmental burden relative to economic development level or income level. Two central questions are addressed in this paper: Is there detectable environmental inequality on a national scale in China? If so, can race and income 
account for this inequality, such as in the U.S., or do other socioeconomic factors specific to China, such as migration and regional differences, play a role?

This paper contributes to the literature on EJ in China in the following ways. First, a "Pyramid Model" that integrates three lenses through which to study EJ in China is proposed and discussed. Then, by using a dataset of nationwide industrial pollution sources obtained from the Chinese Ministry of Environmental Protection (MEP), we conduct a pioneering unit-based empirical analysis of the distribution of environmental inequality at the Chinese prefectural level. To the best of our knowledge, this paper is one of the first studies to provide empirical evidence of environmental inequality based on a comprehensive perspective in China, and it presents a different picture of environmental inequality with respect to minorities and the role of migrants and other groups.

The remainder of our paper is organized as follows. The logic of focusing on EJ issues within the Chinese context is discussed in Section 2, and descriptions of the "Pyramid Model" and the dataset are provided in Section 3. Then, the empirical results and a discussion are presented in Section 4, and conclusions are provided in Section 5 .

\section{Logic of Modelling EJ in China}

Theories and methods produced by EJ studies in the U.S., including studies associated with distributional justice, process justice, corrective justice and social justice [20], can provide valuable information for an EJ research model that is suitable to China. However, because of the considerable differences in social background between China and the U.S., EJ research in China cannot be conducted using race-based models such as those used for the U.S. or by employing an income-based model, which would be too simplistic to provide effective explanations for the Chinese context.

\subsection{Non-Applicability of U.S. EJ Models to China}

\subsubsection{Race-Based EJ Model}

The U.S. is a typical immigrant society that is composed of different ethnic groups, and the indigenous population accounts for less than $5 \%$ of the total population; however, indigenous peoples account for an absolutely dominant proportion of the population in China. While China is a multi-ethnic country, the Han nationality accounts for $91.51 \%$ of China's population [21]. Moreover, ethnic minorities have been gradually assimilated by the Han to different degrees in terms of production and lifestyle. Thus, China's ethnic groups are relatively homogeneous because of mutual integration. On the other hand, communities of different ethnic groups in the U.S. are relatively segregated from one another, and ethnic minorities are often isolated and separated from white society. Despite the nominal elimination of racial discrimination in the U.S. at the institutional and legal levels, racial discrimination (The U.S. Equal Employment Opportunity Commission reported that the discrimination rates with regard to Asian Americans and African Americans are $31 \%$ and $26 \%$, respectively; see detailed information at http:/ / www.humanrights-china.org/china1/newzt/ 2006magezine/200602006424134202.htm (in Chinese)) and even ethnic conflicts are still common problems. However, since the founding of the new China in 1949, the Chinese government has adopted a strict national equality policy to guarantee harmony between ethnic groups. Moreover, minorities in China enjoy more privileges in areas such as employment, fertility and education (see "China in Brief, Population and Ethnic Groups" at http://www.china.org.cn/e-china/population/planning.htm).

In particular, the Chinese central government has established autonomous ethnic regions where local political, economic, and social affairs can be addressed autonomously by minorities [22]. Moreover, preferential economic policies, such as tax exemptions and loans with preferential interest rates for enterprises in autonomous ethnic regions, have been implemented in China. Thus, ethnic minorities' social, economic and political conditions in China are not comparable to those of the ethnic minorities in the U.S. 


\subsubsection{EJ Model from an Income Perspective}

Another major perspective of U.S. EJ research is income, based on the premise that U.S. society is divided into different classes by income level. However, forming a comprehensive explanation of class changes in Chinese society based only on an income flow indicator would be an oversimplification. First, the petty bourgeois society of China is fundamentally different from civil society in Western countries. Western social classes are divided according to cash flow, whereas the social strata in China are divided based mainly on land with multi-functional properties in the form of stock. Second, since the reform and opening up, Chinese society has undergone profound changes, especially the rise of the urban middle class, which originated from the petty bourgeoisie. However, in general, China's social structure is similar to a positive "pyramid", with the petty bourgeoisie accounting for the majority of the population at the base. Compared with the olive-shaped social structure in Western countries, the positive "pyramid" structure of social governance potentially has a higher probability of effectively alleviating certain social justice problems by conforming to the interests of the overwhelming majority of the petty bourgeoisie. Moreover, informal economies in developing countries increase the difficulty of accurately measuring income, thus further implying that it is not appropriate to explore EJ issues in China on an income basis alone. However, if the variables that embody China's special conditions are included in the model, then it is reasonable to assume that income must be controlled for in China's case.

\subsection{Socioeconomic Perspectives of EJ in China}

To conduct a quantitative analysis of environmental inequality in China, a key question concerns which social and economic perspectives should be considered in China's national conditions.

\subsubsection{Household Registration System}

The household registration system is a population management system for the citizens of Mainland China. Once a citizen is born, he/she is assigned a rural or urban household registration status. Under this system, each person must register according to his/her residence; in urban areas, the registration is based on the household, whereas, in rural areas, it is based on the community, village or state farm [23]. The contemporary household registration system began in the late 1950s to limit the migration of the rural population into urban areas because of severe food and energy shortages [24]. However, this policy also improved conditions for urban residents to a greater degree than for rural residents based on food subsidies, employment, housing, health care, the pension system, education, welfare programmes and cultural activities. The household registration system is believed to be the most important determinant of privilege for certain urban residents in China, and it also constitutes the main institutional arrangement governing the inequality between urban and rural areas [23,25]. Because the household registration system directly assigns each person a distinguishable identity, it should be considered the most important indicator when constructing a theoretical model of EJ in the context of China.

\subsubsection{Migrant Population in China}

The restrictions on urban and rural migration associated with the household registration system were gradually relaxed in China in the late 1980s [26], and since then, the mobility of the Chinese population has increased rapidly. China's eastern coastal areas accelerated the development of an export-oriented economy with the introduction of labour-intensive industries, which resulted in a large number of inter-regional labour flows. Moreover, rural migrants, as the main group of migrants, moved from rural lands to find urban jobs because of market reforms and rapid urbanization. (All of the mentioned "migrants" in our paper are people who live outside of the place where he/she was registered through "Hukou" for more than six months within China, without regard to whether the migration was from a rural or urban area or from the eastern or western region. "Rural migrants" refer 
to those migrants who are registered as a rural resident through "Hukou", no matter where he/she is living (migrated to) now. People who migrate from other nations to China are not considered among the "migrant" sample in our study.) In 2013, the total number of rural migrants who work in urban area workers reached 166 million [27]. This massive scale of human migration is unique in the history of the world.

However, the household registration differences result in unequal conditions for rural migrants. (With regard to social status, most migrants in China come from rural areas, referred to as rural migrants, and they have some land in their rural hometown that can guarantee their basic survival. Therefore, they can endure certain unequal conditions, such as relatively lower wages than urban workers and poorer working conditions, a lack of social security and difficulties with their children's education.) Related research has covered multiple aspects of this inequality, including wage gaps [28-30], gender differences [31], occupational isolation [28,32], longer working hours and related health risks [30], profit from education [33,34], education of children [34], living conditions [30,34], and social insurance [34]. Even so, the environmental effects associated with the industrial pollution burden are rarely considered; therefore, migration (especially for rural migrants) must be considered an important issue when exploring EJ in China.

\subsubsection{Urban and Rural Differences}

Since the 1950s, China's industrialization has required a level of accumulation that has necessitated extractions from the rural surplus, leading to the emergence of a systemic structure of urban and rural binary segmentation in China. Due to path dependence, the basic institutional contradictions of this binary segmentation between urban and rural have persisted to the present and have generated significant differences between urban and rural areas. (It is well known that the basic institutional contradiction in China is the contradiction inherent in the binary urban/rural structure. While the contradiction between urban and rural was created by the process of China's industrialization, the existence of this contradiction is the reason that China has experienced an imbalance between institutional benefits and institutional costs over the course of several macroeconomic fluctuations.) Although launched in 2005, the new rural construction policy is considered to be a strategic measure to narrow the differences between rural and urban areas in China; however, the gaps are difficult to fundamentally change overnight because they extend into education, health care, infrastructure, social security, etc. [35]. In terms of environmental inequality, because of the relatively lower costs associated with rural land and labour, pollution-intensive enterprises might be more inclined to locate in grass-roots areas below the county level or in areas with fewer urban residents. Therefore, it is of great practical significance to study environmental inequality from the perspective of urban and rural differences.

\subsubsection{Regional Disparities}

Scholars have conducted comparative analyses of environmental inequality among different regions of the U.S. [3]; however, this subject is not a mainstream research perspective for EJ in the U.S. Unlike in the U.S., regional disparities are considered among the three major gaps encountered in China, with the others being income gaps and urban-rural gaps. Because the eastern region has the highest economic and social development, China has been implementing a series of regional rebalancing strategies, including western development [36], central region improvements [37], and old industrial base revitalization in northeast China [38]. With China's rapid economic growth, the gaps between different regions are expanding rapidly, and the regional gap has become a hot issue in theoretical and practical research. 


\section{3. "Pyramid Model" and Dataset}

\subsection{Baseline "Pyramid Model"}

Based on the above-mentioned perspectives regarding environmental disparities in China, the research model for environmental inequality research can be generally established based on three major factors, which can be functionally stated as follows:

$$
P_{i}=\mathrm{f}\left(D_{i}, U_{i}, C_{i}\right), \quad i=1,2,3
$$

where $P$ represents the burden of sources of pollution, such as industrial pollution sources that are monitored for waste gas, waste water, and sewage treatment; $D$ represents a set of basic demographic variables commonly used in EJ analyses, such as population size and education, among others; $U$ represents the traditional EJ principles developed in the U.S., which are based on race and income; $C$ represents a set of variables that reflect the socioeconomic characteristics that must be examined in the Chinese context, such as migration and regional differences; and $i$ represents geographic units. In particular, the baseline functional model for EJ research in China can be transformed into a three-dimensional "pyramid Model" (shown in Figure 1), with three pyramid bases.

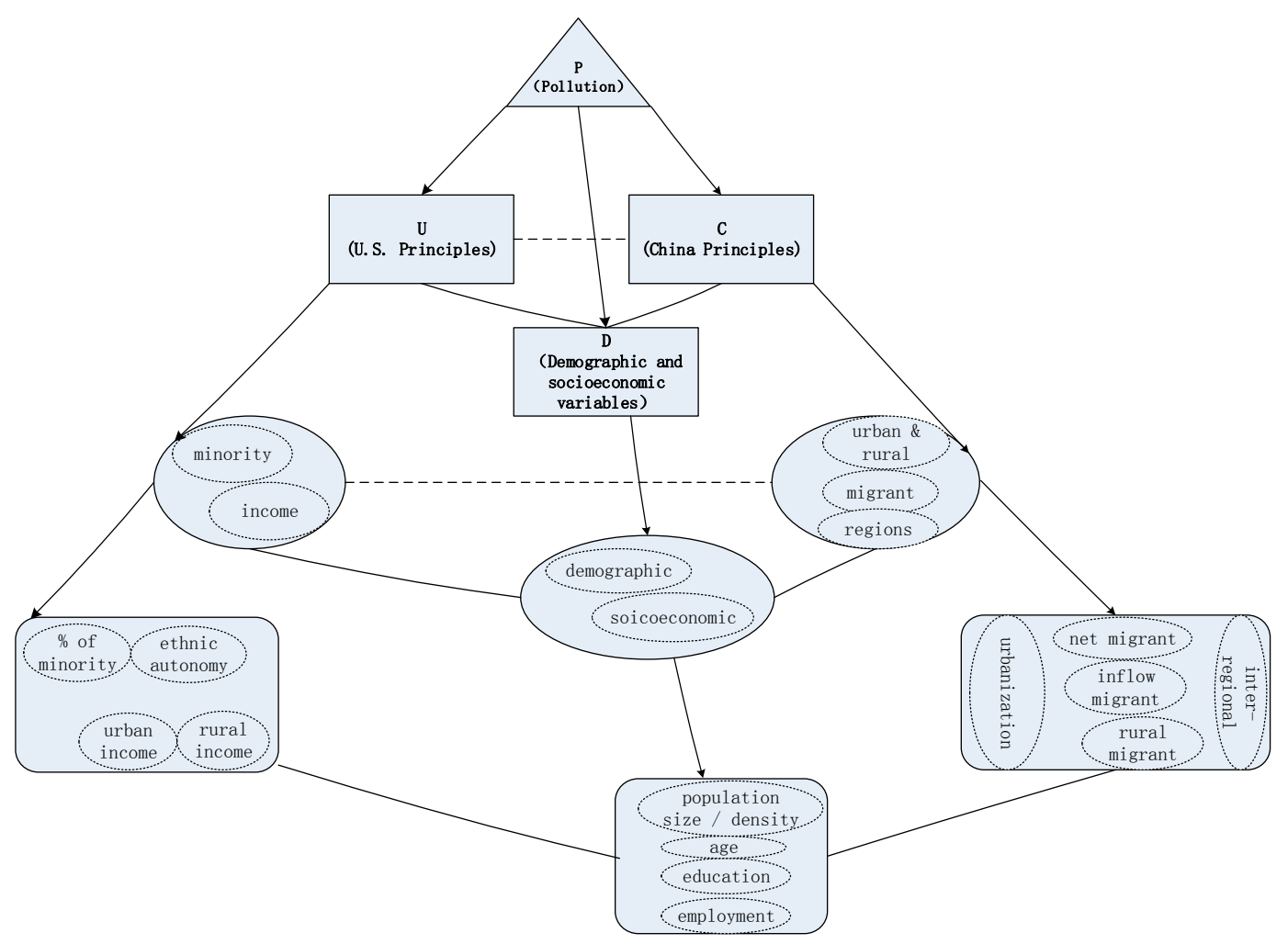

Figure 1. "Pyramid Model" for environmental inequality research in China.

\subsection{Expanded "Pyramid Model" Based on Three Factors}

\subsubsection{Functional Form}

After performing a log-differentiation of Equation (1), we obtain the expanded equation for our baseline analysis, which is based on the three factors shown in Figure 1:

$$
\begin{gathered}
P_{i}=\beta_{0}+\beta_{1} \operatorname{Ln}(\text { psize })_{i}+\beta_{2} \text { midsch }_{i}+\beta_{3} \text { minor }_{i}+\beta_{4} \text { sinc }_{i}+\beta_{5} \text { urban }_{i}+\beta_{6} \text { migrant }_{i}+ \\
\beta_{7} \text { Central }_{i}+\beta_{8} \text { West }_{i}+\beta_{9} \text { Northeast }_{i}+\varepsilon_{i}
\end{gathered}
$$


where $L n$ denotes the natural logarithm, the sub-index $i$ refers to prefecture-level administrative units, $\beta$ represents the parameters to be estimated, and $\varepsilon_{i}$ is the random error. The variable definitions and corresponding data sources in our baseline models are summarized in Table 1, which also shows the variables used for the robustness checks.

\subsubsection{Basic Demographic and Socioeconomic Factors}

Population size $\operatorname{Ln}(p s i z e)_{i}$ (and population density $\operatorname{Ln}(p d e n)_{i}$ ) has been incorporated into the empirical model, as it represents the most critical element in population economics (see Li, 2013 [39]) because people have double roles as both producers and consumers. However, regardless of their role, people are directly and negatively influenced by the pollutants released from industrial production. In addition, because most areas of China are still in the process of industrialization, the local population represents an attractive production factor for the location of labour-intensive polluting enterprises. Thus, pollution from industries concentrated in areas with large populations or their surroundings (e.g., the Yangtze River Delta, the Pearl River Delta and the Beijing-Tianjin-Hebei economic circles) will be more intense, thereby increasing the pollution exposure risk for the residents living in megacities.

Regarding the education factor, people with good education have more flexibility and better opportunities to choose a career with higher income and a healthier working environment because of the accumulation of human capital (see Ministry of Personnel Gazette Human Resources Supply and Demand Information for the First. Time: 10 Specialties Are Most Welcomed by the Market, at http:/ / finance.sina.com.cn/g/20011025/121300.html (25 October 2001) (in Chinese)), and they are more likely to have higher environmental awareness and knowledge of self-protection measures. Therefore, education level $\left(\right.$ midsch $\left._{i}\right)$ has also been included.

\subsubsection{Control Indicators Following U.S. EJ Principles}

As previously discussed for race-based EJ studies in the U.S., ethnic minorities in China do not experience the same social disadvantages as minorities in the U.S., such as African Americans. Nevertheless, whether ethnic minorities who live in areas with extremely high autonomous governance rights experience higher or lower environmental burdens remains unclear. To answer these questions, ethnic-related indicators $\left(\right.$ minor $_{i}$, ethauto ${ }_{i}$ ) must be incorporated into the model to gain a greater perspective on China's case.

Moreover, China is currently in a special era of rapid middle-class growth, which is different from the relatively stable economic, social and political influence of the middle class in developed countries, although the middle class in China potentially enjoys environmental advantages because of their economic advantages. Recalling the meaning of environmental justice, this paper is not focused on environmental inequalities in absolute terms because economic development and environmental pollution are two sides of the same coin for most regions during the process of industrialization. In this study, to evaluate whether geographical units with higher proportions of people with certain demographic and socioeconomic characteristics are disproportionately subjected to environmental burdens relative to their economic development level or income level, income level $\operatorname{sinc}_{i}$ is the most important controlling factor with regard to environmental inequality research in China. 
Table 1. Variable definitions and sources.

\begin{tabular}{|c|c|c|c|}
\hline Category & Variable & Definition & Source \\
\hline $\begin{array}{l}\text { Dependent } \\
\text { variable }\end{array}$ & $P_{i}$ & Number of sources of industrial pollution in unit $i$ as monitored by the MEP in 2010 & MEP \\
\hline \multicolumn{4}{|l|}{$\begin{array}{l}\text { Independent } \\
\text { variables }\end{array}$} \\
\hline \multirow{2}{*}{ D } & $\operatorname{Ln}(p s i z e)_{i}$ & Log of the residential population of geographical unit $i$ & \multirow{2}{*}{ Population Census 2010} \\
\hline & midsch $_{i}$ & Per cent of middle-school-educated residents & \\
\hline \multirow[b]{2}{*}{$\mathrm{U}$} & minor $_{i}$ & $\begin{array}{l}\text { Percent of ethnic minorities (Here, ethnic minorities refer to all fifty-five ethnicities other than the Han } \\
\text { people in China) in the population of geographical unit } i\end{array}$ & Population Census 2010 \\
\hline & $\begin{array}{l}\operatorname{sinc}_{i} \text { (In China, an official discrepancy has occurred in the statistical definition } \\
\text { of urban and rural income, whereby the former represents the per capita } \\
\text { disposable income of urban residents and the latter refers to the per capita net } \\
\text { income of rural households. Therefore, to measure the income level at the } \\
\text { prefecture level, we extract the first principal component of these two } \\
\text { indicators, which accounts for } 91.51 \% \text { of the information) }\end{array}$ & Principal component scores for urban and rural income in geographical unit $i$ & $\begin{array}{l}\text { Authors' calculation } \\
\text { based on the Population } \\
\text { Census } 2010\end{array}$ \\
\hline \multirow{5}{*}{ C } & $u_{\text {rban }}$ & Per cent of the urban population in the total population & \multirow{4}{*}{ Population Census 2010} \\
\hline & netmigi $_{i}$ & $\begin{array}{l}\text { Ratio of permanent resident population to registered population (The registered population refers to } \\
\text { citizens who have registered their permanent residence ("Hukou" in Chinese) with the administrative } \\
\text { department responsible for household registration at their habitual residence, in accordance with "the } \\
\text { housenold registration regulations of the People's Republic of China". According to the } 2010 \text { Population } \\
\text { Census [21, the permanent resident population includes individuals living in townships, towns and } \\
\text { street communities with household registration in the same townships, towns and street communities or } \\
\text { those with household registrations to be determined; individuals living in townships, towns and street } \\
\text { communities who left other registered townships, towns and street communities for more than half a year; } \\
\text { individuals living in townshships, towns and street communities who left the same townships, towns and } \\
\text { street communities for less than half a year; and individuals working or studying abroad. The relation } \\
\text { among the permanent, registered and migrant populations can be summarized in a single equation as } \\
\text { follows: permanent population = registered population + net migrants (flow in).) }\end{array}$ & \\
\hline & $m i g_{i}$ & Per cent of migrants in geographical unit $i$ & \\
\hline & $r m i g_{i}$ & Per cent of rural migrants in geographical unit $i$ & \\
\hline & $\begin{array}{l}\text { Central }_{i} \\
\text { West }_{i} \\
\text { Noreast }_{i}\end{array}$ & $\begin{array}{l}\text { Dummy variable }=1 \text { when unit } i \text { belongs to the central, western or northeastern economic area; } \\
\qquad 0 \text { otherwise. }\end{array}$ & National Statistics Bureau \\
\hline \multirow{5}{*}{$\begin{array}{c}\text { Extended } \\
\text { models }\end{array}$} & $\operatorname{Ln}(\text { area })_{i}$ & Log of the area of geographical unit $i$ & $\begin{array}{l}\text { Statistical yearbooks } 2011 \\
\text { at the provincial level }\end{array}$ \\
\hline & $\overline{L n(p d e n)_{i}}$ & Log of the population density of geographical unit $i$ & Population Census 2010 \\
\hline & polem $_{i}$ & Per cent of employment in mining, manufacturing and electricity generation & Population Census 2010 \\
\hline & $\operatorname{Ln}(\text { watpc })_{i}$ & Log of the average volume of water resources per capita of geographical unit $i$ over the past 3 years & $\begin{array}{l}\text { Water resources bulletin } \\
2008,2009,2010 \text { at } \\
\text { provincial level }\end{array}$ \\
\hline & ethauto $_{i}$ & $\begin{array}{c}\text { Dummy variable }=1 \text { when unit } i \text { is ethnically autonomous at the prefecture level or belongs to the } \\
\text { autonomous region at the provincial level }\end{array}$ & National Statistics Bureau \\
\hline
\end{tabular}

Note: MEP, see details online at http://datacenter.mep.gov.cn/index; Population Census 2010 [21], see details online at http://www.stats.gov.cn/ztjc/zdtjgz/zgrkpc/dlcrkpc/dlcrkpczl/; National Statistics Bureau of China, http:/ / data.stats.gov.cn/; data in Provincial Statistical Yearbooks 2011 and Provincial Water Resources Bulletin 2008, 2009, 2010 are collected from the database of the National Library of China, http://www.nlc.cn/. 


\subsubsection{Indicators Based on the Characteristics of China}

Since the founding of the new China, urbanization has been accompanied by industrialization, which has increased the likelihood that pollution-intensive industries will be located in more urbanized regions. However, urbanization is associated with material wealth, and urban areas have a greater number of initiatives and comparative advantages over rural areas in terms of industry choice and avoiding polluting industries. Thus, given these two completely opposite effect paths, whether more urbanized regions experience a higher or lower industrial pollution burden is the primary research object with regard to environmental inequality in China.

China has the largest number of migrants worldwide, and the basic laws of migration dictate that it occurs from less developed areas to developed areas, from central and western regions of China to eastern areas, and from rural areas to urban areas. Specifically, this paper uses three proxy variables to represent the status of migrants (for unit $i$ ). The first is the ratio of the permanent resident population to the registered population $\left(\right.$ netmig $\left._{i}\right)$, which represents the net population flow. Theoretically, the difference between the registered and permanent resident populations is mainly derived from population flow. Generally, populations may flow from backward areas to developed areas such that the permanent resident population is larger than the registered population in developed regions (and netmig $g_{i}$ is therefore greater than 1 ) and vice versa. The second and third proxies are the percentages of migrants and rural migrants relative to the permanent resident population $\left(m i g_{i}\right.$ and $r m i g_{i}$, respectively).

Moreover, the four major economic regions in China (the eastern, central, western and northeastern regions) differ in their levels of economic development, economic growth patterns and industrial structures, with the eastern region representing the key driver of Chinese economic growth. In our study, three regional dummies are incorporated into the baseline model, and the developed eastern region is used as the benchmark group.

\subsection{Dataset and Estimation Methods}

In accordance with previous EJ research conducted on the U.S., this study presents a unit-based analysis. Typically, the first step of a unit-based EJ analysis is to determine the geographical unit level for the specific study (e.g., census area or zip code in the U.S. context; or province, prefecture, or county in China). Then, comparisons of socioeconomic characteristics between geographical units with and without pollution sources can be carried out. Alternatively, the types of socioeconomic characteristics that dominate in geographical units with more pollution can be determined through statistical methods or econometric models.

In our study, all 337 Chinese geographical units that are administratively classified as belonging to the prefecture level constitute our observation set. (China has five administrative levels: (1) the province level (34), which includes 23 provinces, five autonomous regions, four municipalities and two special administrative regions; (2) the prefecture level (337); (3) the county level (2853); (4) the township level $(40,466)$; and $(5)$ the village level $(691,510)$. The numbers in parentheses indicate the total number of units per level throughout the country at the end of 2010.) Because most of the data from the 2010 census are not publicly available below the prefecture level [21], the prefecture-level geographical units represent the most granular level available for the nationwide analysis in this study.

In addition, two sets of data are required for distributional EJ research: environmental data on sources of pollution and socioeconomic data. A national list of sources of industrial pollution published by the Chinese MEP in 2010 is adopted as the source of environmental data in this study. It includes industrial sites monitored for waste gas (3280 sites), waste water (4146 sites), and sewage treatment (1741 sites) for a total of 8489 sources of industrial pollution, excluding duplicates (678 sites) that are monitored for both waste gas and waste water. Socioeconomic data for all prefectural units are mostly collected from the latest China census, which was conducted in 2010 [21], provincial-level statistical yearbooks for 2011, which report socioeconomic data for prefectures in 2010, and the official website of the Chinese National Statistics Bureau. 
However, because all reported pollution data are obtained from industrial sources, econometric concerns regarding the endogeneity of the income variable because of potential reverse causality must be addressed: namely, more industrial activity may contribute to higher income. To address this issue, a two-stage least squares (2SLS) instrumental variables regression is adopted in this study, and current incomes are instrumented with first- and second-order lags of income. With regard to concerns about possible multicollinearity, the VIFs of models with different control variables are calculated. The VIF scores for all of the independent variables in every model are less than 3 , and the mean VIFs of most models are no greater than 2, which indicates that major multicollinearity issues are not present in our study. For brevity, only the mean VIFs of these models are reported here, with the remaining results available upon request.

\section{Results and Discussion at the Prefecture Level}

\subsection{Baseline Results}

The regression results for the three baseline models based on the 2SLS estimator with instrumental variables are presented in Columns (1)-(3) of Table 2. The signs of the estimated coefficients of the basic demographic variables commonly used in EJ analyses are generally consistent with previous EJ studies. The coefficients of $\operatorname{Ln}(p s i z e)_{i}$ are significantly positive in all the regressions. An increase of $1 \%$ in the population of geographical unit $i$ generates 14 or 15 additional sources of industrial pollution. Thus, residents living in cities with large populations bear a heavier industrial pollution burden, which is partly because the locations for industrial facilities tend to be chosen based on the presence of a complete and mature infrastructure, such as traffic facilities and factories, as well as a high level of market demand and an abundant labour force, such as that found in megacities. The coefficients of midsch $_{i}$ are also positive and significant in all regressions, which is highly consistent with the results of Ma (2010) [18] and Schoolman and Ma (2012) [19]. 
Table 2. Estimation results of baseline models and extended models (2SLS).

\begin{tabular}{|c|c|c|c|c|c|c|c|c|}
\hline \multirow{2}{*}{\begin{tabular}{|l} 
Model \\
Variables \\
\end{tabular}} & \multicolumn{3}{|c|}{$\begin{array}{l}\text { Baseline Models } \\
\text { (As Discussed in Section 3.2.4, Three Different Indicators Associated with the Migrant Population } \\
\text { are Respectively Introduced into the Baseline Models (1)-(3), Including the Ratio of the Permanent } \\
\left.\text { Resident Population to the Registered Population (netmigig and the Percentages of Migrants ( } m \text { ig } g_{i}\right) \\
\text { and Rural Migrants }\left(\text { rmig }_{i}\right) \text { Relative to the Permanent Resident Population.) }\end{array}$} & \multicolumn{5}{|c|}{$\begin{array}{l}\text { Extended Models } \\
\text { (Due to Space Limitations, Only the Results of the Extended Models } \\
\text { Based on Baseline Model (3), with the Percentage of Rural Migrants } \\
\text { Relative to the Total Population }\left(r m i i_{i}\right) \text {, Have been Provided in the } \\
\text { Text, with the Remaining Results Available upon Request.) }\end{array}$} \\
\hline & (1) & (2) & (3) & (4) & (5) & (6) & (7) & (8) \\
\hline Population size $\left(\operatorname{Ln}(p s i z e)_{i}\right)$ & $\begin{array}{c}14.67^{* * *} \\
(2.566)\end{array}$ & $\begin{array}{c}15.34^{* * *} \\
(2.662)\end{array}$ & $\begin{array}{c}14.41^{* * *} \\
(2.562)\end{array}$ & $\begin{array}{c}14.50^{* * *} \\
(2.613)\end{array}$ & $\begin{array}{c}14.43^{* * *} \\
(2.562)\end{array}$ & $\begin{array}{c}14.49^{* * *} \\
(2.596)\end{array}$ & $\begin{array}{l}14.48^{* * *} \\
(2.941)\end{array}$ & $\begin{array}{c}14.13^{* * *} \\
(2.532)\end{array}$ \\
\hline Middle school education $\left(\right.$ midsch $\left._{i}\right)$ & $\begin{array}{c}0.511^{* * *} \\
(0.131)\end{array}$ & $\begin{array}{c}0.373^{* * *} \\
(0.141)\end{array}$ & $\begin{array}{c}0.460^{* * *} \\
(0.137)\end{array}$ & $\begin{array}{c}0.460 * * * \\
(0.137)\end{array}$ & $\begin{array}{c}0.469 * * * \\
(0.14)\end{array}$ & $\begin{array}{c}0.457^{* * *} \\
(0.137)\end{array}$ & $\begin{array}{c}0.466 * * * \\
(0.121)\end{array}$ & $\begin{array}{c}0.290^{* *} \\
(0.126)\end{array}$ \\
\hline Minority $\left(\right.$ minor $\left._{i}\right)$ minor & $\begin{array}{l}0.197 * * * \\
(0.0521)\end{array}$ & $\begin{array}{l}0.208^{* * *} \\
(0.0551)\end{array}$ & $\begin{array}{l}0.183^{* * *} \\
(0.0523)\end{array}$ & $\begin{array}{l}0.184^{* * *} \\
(0.0528)\end{array}$ & $\begin{array}{l}0.180^{* * *} \\
(0.0524)\end{array}$ & $\begin{array}{l}0.188^{* * *} \\
(0.0546)\end{array}$ & $\begin{array}{l}0.182 * * * \\
(0.0543)\end{array}$ & \\
\hline $\begin{array}{c}\text { Income level } \\
\left(\operatorname{sinc}_{i}\right)\end{array}$ & $\begin{array}{c}11.85^{* * *} \\
(2.803)\end{array}$ & $\begin{array}{c}11.80^{* * *} \\
(2.658)\end{array}$ & $\begin{array}{c}12.39^{* * *} \\
(2.764)\end{array}$ & $\begin{array}{c}12.41^{* * *} \\
(2.758)\end{array}$ & $\begin{array}{c}12.42^{* * *} \\
(2.755)\end{array}$ & $\begin{array}{l}12.08^{* * *} \\
(2.8)\end{array}$ & $\begin{array}{c}12.44^{* * *} \\
(2.864)\end{array}$ & $\begin{array}{c}11.81^{* * *} \\
(2.697)\end{array}$ \\
\hline $\begin{array}{l}\text { Urbanization } \\
\quad\left(\text { urban }_{i}\right)\end{array}$ & $\begin{array}{l}-0.068 \\
(0.0525)\end{array}$ & $\begin{array}{c}0.215 \\
(0.131)\end{array}$ & $\begin{array}{l}-0.0195 \\
(0.0536)\end{array}$ & $\begin{array}{l}-0.0219 \\
(0.0534)\end{array}$ & $\begin{array}{l}-0.0162 \\
(0.0533)\end{array}$ & $\begin{array}{l}-0.0259 \\
(0.0583)\end{array}$ & $\begin{array}{l}-0.019 \\
(0.0546)\end{array}$ & $\begin{array}{l}-0.021 \\
(0.0601)\end{array}$ \\
\hline $\begin{array}{l}\text { Net migration } \\
\left(\text { netmigi }_{i}\right)\end{array}$ & $\begin{array}{c}-12.79 * * * \\
(3.279)\end{array}$ & & & & & & & \\
\hline Migrants $\left(m i g_{i}\right)$ & & $\begin{array}{c}-0.560^{* * *} \\
(0.207)\end{array}$ & & & & & & \\
\hline Rural migrants $\left(r m i g_{i}\right)$ & & & $\begin{array}{c}-0.524^{* * *} \\
(0.194)\end{array}$ & $\begin{array}{c}-0.526^{* * *} \\
(0.193)\end{array}$ & $\begin{array}{c}-0.541^{* * *} \\
(0.191)\end{array}$ & $\begin{array}{c}-0.561^{* * * *} \\
(0.196)\end{array}$ & $\begin{array}{c}-0.531^{* * * *} \\
(0.199)\end{array}$ & $\begin{array}{c}-0.516^{* * *} \\
(0.18)\end{array}$ \\
\hline $\begin{array}{l}\text { Central region } \\
\left(\text { Central } l_{i}\right)\end{array}$ & $\begin{array}{l}3.132 \\
(3.43)\end{array}$ & $\begin{array}{c}3.514 \\
(3.395)\end{array}$ & $\begin{array}{l}2.857 \\
(3.382)\end{array}$ & $\begin{array}{l}2.82 \\
(3.37)\end{array}$ & $\begin{array}{c}2.78 \\
(3.393)\end{array}$ & $\begin{array}{l}3.208 \\
(3.515)\end{array}$ & $\begin{array}{l}2.854 \\
(3.38) \\
\end{array}$ & $\begin{array}{l}1.905 \\
(3.475) \\
\end{array}$ \\
\hline $\begin{array}{l}\text { Western region } \\
\left(\text { West }_{\text {) }} \text { WESTi }\right.\end{array}$ & $13.20^{* * *}$ & $14.53^{* * *}$ & $13.61^{* * *}$ & $13.61^{* * * *}$ & $13.62^{* * *}$ & $14.23^{* * *}$ & $13.72^{* * *}$ & $11.76^{* *}$ \\
\hline $\begin{array}{c}\text { Northeastern region } \\
\left(\text { Noreast }_{i}\right)\end{array}$ & $\begin{array}{l}(4.813) \\
-7.243^{*} \\
(3.923)\end{array}$ & $\begin{array}{l}(5.042) \\
-9.700)^{* *} \\
(3.97)\end{array}$ & $\begin{array}{l}(4.677) \\
-9.319^{* *} \\
(4.107)\end{array}$ & $\begin{array}{c}(4.658) \\
-9.310^{* *} \\
(4.117)\end{array}$ & $\begin{array}{l}(4.681) \\
-9.5488^{* *} \\
(4.144)\end{array}$ & $\begin{array}{l}(5.067) \\
-8.723^{* *} \\
(4.432)\end{array}$ & $\begin{array}{l}\frac{(5.277)}{-9.39)^{* *}} \\
(3.892)\end{array}$ & $\begin{array}{l}(4.816) \\
-7.991 * * \\
(4.06)\end{array}$ \\
\hline $\begin{array}{l}\text { Geographical area } \\
\left(\text { Ln }(\text { area })_{i}\right)\end{array}$ & & & & $\begin{array}{c}0.664 \\
(1.006) \\
\end{array}$ & & & & \\
\hline Population density $\left(\operatorname{Ln}(p d e n)_{i}\right)$ & & & & & $\begin{array}{l}-0.574 \\
(1.137)\end{array}$ & & & \\
\hline $\begin{array}{l}\text { Employment in polluting industry } \\
\left(\text { polem }_{i}\right)\end{array}$ & & & & & & $\begin{array}{l}0.0901 \\
(0.205)\end{array}$ & & \\
\hline $\begin{array}{c}\text { Water resources } \\
\left(\operatorname{Ln}\left(\text { wat } p c_{i}\right)\right.\end{array}$ & & & & & & & $\begin{array}{r}0.122 \\
(1.097) \\
\end{array}$ & \\
\hline Ethnic autonomous (ethauto $\left.{ }_{i}\right)$ & & & & & & & & $\begin{array}{c}7.615^{* * *} \\
(2.549)\end{array}$ \\
\hline Constant & $\begin{array}{c}-211.4 * * * \\
(38.57)\end{array}$ & $\begin{array}{l}-230.3 * * * * \\
(40.91)\end{array}$ & $\begin{array}{c}-214.2^{* * *} \\
(39)\end{array}$ & $\begin{array}{c}-218.7 * * * \\
(42.15)\end{array}$ & $\begin{array}{c}-212.4^{* * *} \\
(39.1)\end{array}$ & $\begin{array}{c}-216.5 * * * \\
(40.2)\end{array}$ & $\begin{array}{c}-216.5^{* * *} \\
(51.79)\end{array}$ & $\begin{array}{l}-204.2^{* * * *} \\
(37.64)\end{array}$ \\
\hline$p$-value of Sargan statistic & 0.2816 & 0.3448 & 0.3200 & 0.3104 & 0.3323 & 0.3013 & 0.3229 & 0.902 \\
\hline$p$-value of Wu-Hausman F-statistic & 0.0071 & 0.0086 & 0.0081 & 0.0084 & 0.0075 & 0.0122 & 0.0084 & 0.0886 \\
\hline Observations & 337 & 337 & 337 & 337 & 337 & 337 & 337 & 337 \\
\hline$R$-squared & 0.392 & 0.394 & 0.387 & 0.388 & 0.388 & 0.39 & 0.387 & 0.384 \\
\hline Mean VIF & 1.83 & 2.65 & 1.95 & 1.85 & 1.88 & 2.28 & 2.03 & 1.85 \\
\hline
\end{tabular}

Note: Robust standard errors are in parentheses. The Sargan test of over-identifying restrictions is a test of the joint null hypothesis that the instruments are valid. Wu-Hausman tests of endogeneity evaluate the null hypothesis that all the independent variables in the model should be treated as exogenous. ${ }^{* * *} p<0.01$, $^{* *} p<0.05,{ }^{*} p<0.1$. 
From the perspective of U.S. EJ principles, it is interesting to find that minorities in China suffer from relatively disproportionate environmental burdens based on our estimates. The coefficients of minor $_{i}$ are significantly positive in all the regressions in Table 2 , indicating that a $10 \%$ increase in the proportion of minorities within the total population in unit $i$ may be associated with approximately two additional sources of industrial pollution. Possible reasons for these results may be that most minorities in China live in prefectures with abundant natural resources, such as water and minerals, which make them attractive locations for industrial sites. Most importantly, the governance of minorities in China is characterized by ethnic autonomy, whereby the Chinese central government authorizes local governments to benefit from many privileges in the name of self-governance. Whether ethnic autonomy plays a role in the disproportionate burden of industrial pollution placed on minorities is investigated in the extended models.

Several U.S. EJ studies suggest that there are serious environmental inequalities associated with income level [40,41], with the poor being exposed to more environmental pollution than the middle class. However, such inequalities do not appear to be the case with administrative units at the prefecture level in China. The coefficients of $\operatorname{sinc}_{i}$ are positive and significant at the $1 \%$ level, which implies that people living in prefectures that benefit greatly from industrial activities in terms of higher income levels are also more likely to bear a higher industrial environmental burden. This finding is in accordance with the results of Ma (2010) [18], who also indicated that the poor do not suffer more from environmental pollution than the rich in China because of social and economic differences between the U.S. and China. Generally, China is still at the stage in which industrial capital dominates development, whereas Western countries, especially the U.S., have entered the phase in which financial capital dominates. Therefore, in this paper, which analyses observations from China, the results related to income level differ completely from those of traditional U.S. EJ research, for which the observations are from the U.S.

However, caution must be exercised when interpreting the role of the urbanization of unit $i$ with regard to the burden of industrial environmental pollution. The insignificant coefficients of $\operatorname{urban}_{i}$ indicate that the urbanization rate is not an explicit predictor of the number of sources of industrial pollution within unit $i$; thus, related factors must be considered as well. With the Chinese government's continuous investments in construction in the central and western regions since the beginning of the new century and new rural construction since 2005, urbanization has been integrated into industrialization in central and western Chinese cities; however, because of the global financial crisis of 2008, a greater trend towards de-industrialization has been observed in coastal Chinese cities, whose urbanization rates are relatively higher than those of central and western cities. Thus, as a result of both of these trends, the burden of industrial pollution may not be significantly related to the urbanization rate in China.

Regarding the migrant variables, the significant negative coefficients associated with the migrant variables generally exceeded our expectations; these results represent one of the most important lenses in our study. Higher ratios of permanent resident population to registered population and higher proportions of migrants or rural migrants relative to permanent residents are all associated with fewer sources of industrial pollution in unit $i$.

Notably, the estimation results related to migrants are different from those observed by Ma (2010) [18] and Schoolman and Ma (2012) [19], which necessitates a systematic interpretation. The data associated with migrants used in previous studies $[18,19]$ were collected from the 2000 China census; at that time, migrants were mainly engaged in labour-intensive industries that produce high levels of pollution, such as the mining and textile industries. However, the analysis in this paper is based on the latest census data from 2010, and the ratio of migrants working in business or services in China increased from $22.29 \%$ in 2000 to $31.28 \%$ in 2010. Currently, Chinese migrants, especially rural migrants, have mostly clustered in the construction industry and the service industries, including catering and logistics, which are not included in the sample of industrial sources of pollution in our paper. In addition, substantial changes in the educational levels of migrants are an important factor 
underlying the structural changes in their occupations. In 2000, 22.90\% of Chinese migrants had an education at the elementary school level and below and $14.14 \%$ at the college degree level or above; however, these figures had shifted to $19.07 \%$ and $18.92 \%$, respectively, by 2010 . In the case of rural migrants, these figures shifted from $28.83 \%$ in 2000 to $22.76 \%$ in 2010 with regard to education at the elementary school level and below, and from $5.72 \%$ to $9.13 \%$, respectively, with regard to education at college degree level or above.

However, it is known that Chinese migrants mainly cluster in the coastal provinces (according to the 2010 China census, $51.48 \%$ of migrants and $57.66 \%$ of rural migrants in the overall national migrant population flowed into eastern regions), where the industrial structures are undergoing a transformation into capital- and technology-intensive industries and tertiary industries. Deindustrialization in eastern areas has been encouraging industries to transfer into the central and western regions, particularly pollution-intensive industries. For the central and western regions of China, the average ratios of industrial value-added to GDP were $33.95 \%$ and $30.05 \%$, respectively, in 2000 and reached $45.49 \%$ and $38.53 \%$, respectively, in 2010. From the perspective of employment data, the ratios of employment in mining, manufacturing, and the production and supply of electric power, gas and water from 2000 to 2010 also increased by $5.04 \%$ and $1.74 \%$ in the central and western regions, respectively. In addition, worse living conditions, such as lower income levels (in 2010, the per capita disposable yearly income of urban residents in the eastern, central, western and northeastern regions of China was 20,876,15,914,14,322 and 15,502 RMB, respectively, and the per capita net yearly income of rural residents was $8780,5703,4786$ and $7422 \mathrm{RMB}$, respectively), in the central and western regions compared with the coastal areas have led to population outflows from the former two areas (the ratios of the permanent resident population to the registered population in eastern, central, western and northeastern China were 1.1588, 0.9333, 0.9768 and 1.0048 in 2010, respectively). Based on the comprehensive effects of these factors, the coefficients of migrants are negative.

Furthermore, from the perspective of regional differences, the coefficients of the dummies for CENTRAL $L_{i}, W E S T_{i}$ and NORTHEAST $T_{i}$ are insignificantly positive, significantly positive and significantly negative, respectively, which indicates that there are obvious regional disparities in terms of environmental inequality in China, with the western region suffering from a disproportionate amount of industrial pollution relative to its level of development.

As with any major economy covering a large geographic area, obvious regional differences in the levels of development are observed across China, which has led to significant readjustments to the regional development strategy. Since the reform and opening up began in the late 1970s, national and foreign investment as well as industrial facilities have become concentrated in eastern coastal areas. This unbalanced regional strategy has contributed to rapid economic growth in the coastal areas, making the Pearl River Delta and Yangtze River Delta regions the "engines" driving the high-speed growth of the Chinese economy. However, this unbalanced strategy, which presents greater agglomeration effects than spillover effects, also leads to greater regional differences, especially with regard to continuous growth in the gaps between the eastern and western regions. After 1991, to prevent the widening of this regional gap from triggering "polarization", regional coordinated development became the national strategic focus, which divided China into four economic regions (eastern, central, western and northeastern regions). Since 1999, the Chinese government has begun to implement the strategy of "Western Development". Beyond the strengthening of infrastructure, the Chinese government has facilitated the transformation of resource advantages, such as energy and mineral resources, into industrial advantages in western areas. Specifically, since 2003, the optimization and upgrading of industrial structures and industrial transfers from eastern regions has been supported, and the development of advanced manufacturing, high technology and service industries has been prioritized. In the context of deindustrialization, the eastern region has been encouraged to assist in the development of the more backward central and western areas, which further increases the possibility that the central and western areas will accommodate the transfer of polluting industries from the east. However, because of the development of modern agricultural 
techniques and the economic transformation of resource-exhausted cities, the northeastern area has not suffered from disproportionate industrial pollution.

\subsection{Discussion Based on a Broader Perspective}

Furthermore, to determine whether some other variables derived from common sense or suggested by previous studies $[18,19]$ could potentially have substantial impacts on our EJ modelling, several extended models were investigated, with the results summarized in Table 2.

Specifically, because the 337 prefectural units differ significantly in terms of land area and because geographical units with larger areas may tend to have higher capacities to host industrial activities, including pollution sites, $\operatorname{Ln}(\text { area })_{i}$ was examined first to determinewhether land area plays a part in industrial pollution in Regression (4) of Table 2. However, this variable was shown to be empirically non-significant for prefectures in China. China is a large country with diverse a topography, including mountains and hills and plains, among others. The locations of industrial enterprises seem to be highly correlated with topographies that provide better access to infrastructure, such as plains, rather than with land area itself. Next, in addition to the lenses included in our baseline model, Regression (5) incorporates population density $\left(\operatorname{Ln}(p d e n)_{i}\right)$, which may play a role in environmental inequality. Again, on the one hand, due to the impact of geographical area as a denominator, $\operatorname{Ln}(p d e n)_{i}$ is not statistically significant, even without population size $\left(\operatorname{Ln}(p s i z e)_{i}\right)$ included in the model (results available upon request). On the other hand, most areas with high population density are concentrated in the eastern coastal provinces of China, which are undergoing industrial transformation and upgrading. This may offset the positive appeal of the population as a labour input and result in insignificant regression parameters.

In addition, Ma (2010) [18] suggested that there may be a need to control for the potential tendency of rural migrants to work in pollution-intensive industries, so employment in polluting industries $\left(\right.$ polem $_{i}$ ) is incorporated into the baseline Model (3) with $\mathrm{rmig}_{i}$ forming Regression (6). The results show that when controlling for employment in polluting industries, the significance of the key variables in this study is highly consistent with the results of the baseline models. In addition, locations with water resources represent attractive sites for sources of industrial pollution [18,19]; therefore, $\operatorname{Ln}(\text { wat } p c)_{i}$ has been incorporated into Regression (7). However, with China's western development and the shutting down of out-dated production facilities in the eastern region, polluting enterprises have moved to the relatively water-scarce western region, which makes $\operatorname{Ln}(\text { wat } p c)_{i}$ statistically insignificant for prefectures in China as a whole.

Finally and most importantly, the Chinese government has authorized certain prefectural units inhabited by ethnic minorities to benefit from local self-governance, whereby policy-making associated with industrial pollution can be autonomous. Thus, ethauto $i$ has been included in Regression (8), replacing minor ${ }_{i}$, to detect whether ethnic autonomy provides more favourable conditions for pollution or whether a discriminatory tendency in the distribution of industrial pollution sites per se is observed. Specifically, the results from Regression (8) indicate that ethnic autonomy plays a role in the distribution of industrial pollution sites. As for the potential reasons an uneven environmental burden is borne by ethnic minority autonomous regions, first, since China's reform and opening up, local authorities in China have been gradually evolving into corporatist governance by pursuing economic growth and fiscal revenue and competing to establish industrial development zones. A higher level of autonomy accompanied by the faster development of industrialization may result in a higher possibility of industrial pollution. In addition, since the beginning of the new century, China's central government has been gradually taking back power from most local authorities while giving relatively more self-governance rights to the autonomous governments, thus allowing industrialization to continue with its more serious environmental problems. Second, as most ethnically autonomous regions are located in remote areas in China, to raise people's standard of living, local governments have formulated a "big industries" strategy that aims to accelerate modernization via industrialization. Moreover, most autonomous regions have rich mineral resources such as coal, rare earths, oil and 
gas in Inner Mongolia (see details in "General Planning of Mineral Resources in Inner Mongolia (2008-2015)" issued by the Land and Resources Office of Inner Mongolia, available online at http: //www.nmggtt.gov.cn/zwgk/ghjh/kczygh/201005/t20100513_27500.htm (in Chinese)) and iron and copper, oil, natural gas and coal in Xinjiang (see details in "General Planning of Mineral Resources in Xinjiang (2008-2015)" issued by the Land and Resources Office of Xinjiang, available online at http:/ / www.mlr.gov.cn/kczygl/kcgh/201012/t20101209_800635.htm (in Chinese)). Thus, pollution-intensive industries dominate in those areas.

Moreover, although our study shows similar empirical results to the U.S. context with regard to minorities in China, the reasons underlying the disproportionate share of environmental burdens are essentially different, which requires careful interpretation. Both American Indians and Chinese minorities are aboriginal within their continents, but their status within their countries and their relationship with the majorities (whites in the U.S. and the Han in China) are essentially different. With regard to development (including environmental rights), U.S. Native American reservations are not treated equally, resulting in heavier environmental pollution burdens, which contrast with the privileges and autonomy in China's autonomous ethnic minority areas, who enjoy economic growth, local taxes and employment from industrial enterprises; thus, they bear more of the costs of environmental pollution.

In addition, although mentioned in the "Pyramid Model" of EJ in China, age structure indicators are not shown for the baseline and extended empirical models in our study because age groups as a percentage of the population show little variation among prefectures in China, with a coefficient of variation of only $0.41 \%$ for percentage of working age, which is not sufficiently significant to indicate differentiated empirical results for China's prefectures. A similar conclusion can be drawn with regard to employment indicators. The results incorporating age structure and unemployment indicators can be provided upon request.

In summary, the results of the key variables in the extended models are qualitatively similar to those in the baseline models, suggesting that our baseline modelling is rational and robust across different specifications.

\subsection{Limitations}

Although this study has provided new insights related to environmental inequality from industrial pollution in China, it is important to note the limitations of the study and the potential to extend the study over time. An obvious point is that the findings are only applicable at the prefecture level in China, resulting in limited explanatory capability for the urban-rural lens. Additional work should be conducted to obtain a better understanding of the implications of China's EJ issues within smaller administrative units, such as the county or even township and village levels. Moreover, the unit-based methodology adopted in this study is based on the premise that every single pollution source has a similar pollution capacity, which may be unrealistic in practice. Better access to pollution exposure data, especially pollution concentrations based on Geographic Information System (GIS) data, must be promoted in the future to generate more targeted results for exposure- or risk-based EJ studies for China. Further studies could certainly be refined by incorporating diverse pollution sources, including, but not limited to, rural hazards. Moreover, the results indicating an unequal distribution of the sources of industrial pollution, including the results related to minorities, are subject to the model specifications. Although some remaining problems could not be fully explored in this paper using the current unit-based EJ methodology at the prefectural level in China, this paper may still provide some informative results and meaningful implications for reference and discussions of EJ practices in China.

\section{Conclusions}

Interesting conclusions were derived from this paper's empirical unit-based analysis of the distributional environmental inequality at the prefectural level in China. First, the paper's empirical results indicate that environmental inequalities occur in China based on certain demographic and 
socioeconomic characteristics, and these inequalities are robust across different model specifications. Second, our empirical evidence suggests that minorities in China disproportionately bear the burden of industrial pollution, which is partly due to the ethnic autonomy of local governments authorized by the Chinese central government. Third, the results associated with income level are consistent with those in Ma (2010) [18] and Schoolman and Ma (2012) [19], which indicates that environmental inequality based on income level, such as in the U.S., does not occur in Chinese prefectures. However, this paper presents a different perspective of the relationship of migrants with sources of industrial pollution in China than was provided in previous studies. Based on the combined effects of regional industrial transfers and enterprises as well as changes in the educational attainment levels and occupations of migrants, Chinese migrants are not currently disproportionately exposed to industrial pollution. In addition, mixed results were obtained with regard to regional environmental inequalities, as the western region of China seems to suffer heavily from the environmental inequalities generated by the new national policy on regional development implemented by the Chinese government in the new century. Hopefully, the results of this pilot analysis of nationwide environmental inequality in China may inspire additional research on China's EJ issues.

Acknowledgments: The research was funded by the National Key R\&D Program of China (2016YFA0602604), the China Postdoctoral Science Foundation (2016M591143), the Natural Science Foundation of China (71273022; 71773006; and 71420107025) and the Basic Research Fund of the Chinese Academy of Agricultural Sciences (2017). The authors also thank the ESRC Centre for Climate Change Economics and Policy (CCCEP) at the University of Leeds for providing support and the anonymous reviewers for their time and effort in improving this publication.

Author Contributions: Qi He and Hong Fang conceived and designed the research; Qi He, Han Ji and Siran Fang collected the data; Qi He and Han Ji performed the calculations and analysed the results; Hong Fang and Siran Fang contributed discussions; Qi He drafted the paper; and all authors contributed to editing the manuscript.

Conflicts of Interest: The authors declare no conflict of interest.

\section{References}

1. Bullard, R.D. Solid waste sites and the black Houston community. Sociol. Inq. 1983, 53, 273-288. [CrossRef] [PubMed]

2. General Accounting Office (GAO). Siting of Hazardous Waste Landfills and Their Correlation with Racial and Economic Status of Surrounding Communities; U.S. General Accounting Office: Gaithersburg, MD, USA, 1983.

3. Commission for Racial Justice (CRJ). Toxic Wastes and Race in the United States: A National Report on the Racial and Socio-Economic Characteristics of Communities with Hazardous Waste Sites; United Church of Christ Commission for Racial Justice: New York, NY, USA, 1987.

4. Brown, P. Race, class, and environmental health: A review and systematization of the literature. Environ. Res. 1995, 69, 15-30. [CrossRef] [PubMed]

5. Gao, O.H.; Klein, R.A. Environmental equity in participation of the clean air school bus program: The case of New York State. Transp. Res. Part D Transp. Environ. 2010, 15, 220-227. [CrossRef]

6. Gao, O.H.; Klein, R.A. Environmental equity in funding decisions of the clean air school bus program: The case of New York State. Transp. Res. Part D Transp. Environ. 2011, 16, 10-14. [CrossRef]

7. Szasz, A.; Meuser, M. Unintended, inexorable: The production of environmental inequalities in Santa Clara County, California. Am. Behav. Sci. 2000, 43, 602-632. [CrossRef]

8. Pastor, M.; Sadd, J.; Hipp, J. Which came first? Toxic facilities, minority move-in, and environmental justice. J. Urban Aff. 2001, 23, 1-21. [CrossRef]

9. Mohai, P.; Saha, R. Reassessing racial and socioeconomic disparities in environmental justice research. Demogr. 2006, 43, 383-399. [CrossRef]

10. Mohai, P.; Saha, R. Racial inequity in the distribution of hazardous waste: A national-level reassessment. Soc. Probl. 2007, 54, 343-370. [CrossRef]

11. Morello-Frosch, R.; Pastor, M.; Sadd, J. Environmental justice and southern California's 'riskscape' -The distribution of air toxics exposures and health risks among diverse communities. Urban Aff. Rev. 2001, 36, 551-578. [CrossRef] 
12. Ash, M.; Fetter, T.R. Who lives on the wrong side of the environmental tracks? Evidence from the EPA's risk-screening environmental indicators model. Soc. Sci. Q. 2004, 85, 441-462. [CrossRef]

13. Morello-Frosch, R.; Jesdale, B.M. Separate and unequal: Residential segregation and estimated cancer risks associated with ambient air toxics in the U.S. metropolitan areas. Environ. Health Perspect. 2006, 114, 386-393. [CrossRef] [PubMed]

14. Dasgupta, S.; Wheeler, D. Citizen Complaints as Environmental Indicators: Evidence from China; Policy Research Working Paper Series 1704; The World Bank: Washington, DC, USA, 1997; Available online: http:/ / documents.worldbank.org/curated/en/450781468746709957/pdf/multi-page.pdf (accessed on 1 September 2014).

15. Knup, E. Environmental NGOs in China: An overview. China Environ. Serv. 1997, 1, 9-15.

16. Brettell, B.A. Environmental disputes and public service law: Past and present. China Environ. Serv. 2002, 4, 66-69.

17. Quan, R.X. Establishing China's environmental justice study models. Georget. Int. Environ. Law Rev. 2001, 14, 461-487.

18. Ma, C.B. Who bears the environmental burden in China-An analysis of the distribution of industrial pollution sources? Ecol. Econ. 2010, 69, 1869-1876. [CrossRef]

19. Schoolman, E.D.; Ma, C.B. Migration, class and environmental inequality: Exposure to pollution in China's Jiangsu Province. Ecol. Econ. 2012, 75, 140-151. Available online: https:/ /www.highbeam.com/doc/1P3121911732.html (accessed on 1 September 2014). [CrossRef]

20. Kuehn, R.R. A taxonomy of environmental justice. Environ. Law Rep. 2000, 30, 10681-10700. Available online: https:/ / ssrn.com/abstract=628088 (accessed on 5 September 2014).

21. China Census (CC). The Sixth National Population Census, National Bureau of Statistics of China. 2010. Available online: http://www.stats.gov.cn/ztjc/zdtjgz/zgrkpc/dlcrkpc/dlcrkpczl/ (accessed on 7 September 2014).

22. Zhang, H. The laws on ethnic minority autonomous regions in China: Legal norms and practice. Soc. Sci. Electron. Pub. 2012, 2, 249. Available online: https://ssrn.com/abstract=2029781 (accessed on 17 August 2017).

23. Liu, Z. Institution and inequality: The Hukou system in China. J. Comp. Econ. 2005, 33, 133-157. [CrossRef]

24. Cheng, T.; Selden, M. The origins and social consequences of China's Hukou system. China Q. 1994, 139, 644-668. [CrossRef]

25. Wu, X.; Treiman, D.J. The household registration system and social stratification in China: 1955-1996. Demography 2004, 41, 363-384. [CrossRef] [PubMed]

26. Chan, K.W.; Zhang, L. The Hukou system and rural-urban migration in China: Processes and changes. China Q. 1999, 160, 818-855. Available online: http:/ /www.jstor.org/stable/656045 (accessed on 7 July 2017). [CrossRef]

27. National Bureau of Statistics (NBS) of China. National Report on Rural Migrants in 2013. Available online: http:/ / www.stats.gov.cn/tjsj/zxfb/201405/t20140512_551585.html (accessed on 12 May 2014).

28. Meng, X.; Zhang, J. The two-tier labor market in urban China: Occupational segregation and wage differentials between urban residents and rural migrants in Shanghai. J. Comp. Econ. 2001, 29, 485-504. [CrossRef]

29. Meng, X. Profit Sharing and the Earnings Gap between Urban and Rural-Migrant Workers in Chinese Enterprises; Working Paper; Department of Economics, Research School of Pacific and Asian Studies, Australian National University: Canberra, Australia, 2006; Available online: http:/ / people.anu.edu.au/xin.meng/MIGRANT4version2.pdf (accessed on 1 May 2015).

30. Wang, R. The Welfare of Rural Migrant Workers; Working Paper; Institute of Population and Labor Economics, Chinese Academy of Social Sciences: Beijing, China, 2009.

31. Huang, Y. Gender, Hukou, and the occupational attainment of female migrants in China (1985-1990). Environ. Plan. A 2001, 33, 257-280. [CrossRef]

32. Roberts, K.D.; Chen, A.; Liu, G.G.; Zhang, K.H. The determinants of job choice by rural labor migrants in Shanghai. China Econ. Rev. 2001, 12, 15-39. [CrossRef]

33. Knight, J.; Song, L.; Jia, H. Chinese rural migrants in urban enterprises: Three perspectives. J. Dev. Stud. 1999, 35, 73-104. [CrossRef] 
34. Wei, Y. Rural-urban migrant workers in China: The vulnerable group in cities. In Proceedings of the 6th the Berlin Roundtables on Transnationality on 'Population Politics and Migration', Berlin, Germany, 14 February 2007.

35. Lu, Y.L. Peasant China: Study of Post-Earthbound Society and New Rural Construction; China Renmin University Press: Beijing, China, 2010.

36. Shih, V. Development, the second time around: The political logic of developing western China. J. East Asian Stud. 2004, 4, 427-451. [CrossRef]

37. Zhu, T. Resource and comparative advantages and industrial choice for the central region's rising in China. Prod. Res. 2007, 18, 109-110. (In Chinese)

38. Xiang, W.; Qian, Q.L.; Sheng, K.R.; Fan, J. Comparison and thoughts of "great western development" and "revitalization of the old industrial base in northeast china" strategy: Discussion of the scientific meaning and contents of national region development strategy. Econ. Geogr. 2006, 6, 902-918. (In Chinese)

39. Li, Z.S. Population Economics, 3rd ed.; Tsinghua University Press: Beijing, China, 2013.

40. Krieg, E.J.; Faber, D.R. Not so black and white: Environmental justice and cumulative impact assessments. Environ. Impact Assess. Rev. 2004, 24, 667-694. [CrossRef]

41. Bevc, C.A.; Marshall, B.K.; Picou, J.S. Environmental justice and toxic exposure: Toward a spatial model of physical health and psychological well-being. Soc. Sci. Res. 2007, 36, 48-67. [CrossRef]

(C) 2017 by the authors. Licensee MDPI, Basel, Switzerland. This article is an open access article distributed under the terms and conditions of the Creative Commons Attribution (CC BY) license (http://creativecommons.org/licenses/by/4.0/). 